\title{
Numerical analysis of a heat exchanger with differentiated temperatures surface at varying distances from the wall
}

\author{
Magdalena Orłowska ${ }^{1, *}$ \\ ${ }^{1}$ Technical University of Koszalin, Faculty of Civil Engineering, Environmental and Geodetic \\ Sciences, al. Śniadeckich 2, 75-453 Koszalin, Poland
}

\begin{abstract}
This article is one of a series of articles by the author. For many years she conducts research on convective heat exchange. The work is mainly concerned on knowing the effect of positioning the heater on the heat output of the device. It turns out that the correct location is very important.
\end{abstract}

\section{Introduction}

When installing a radiator, we have to take many considerations into account, such as a wall with a window or interior, the distance from the floor and the sill or wall. It is also important to consider additional decorative covers.

This article is a follow-up to the author's series on airflow for radiators operating under different boundary conditions.

\subsection{Convection heat transfer and radiators}

Convection occurs when we are dealing with the macroscopic movement of fluid particles (liquid or gas) in the direction of temperature drop. The movement of fluid molecules determines the heat flux and the temperature field. This term refers to the case of the energy flow between the moving fluid and the surface of the barrier at different baffle and plate temperatures. We divide it into natural and forced. With forced velocity fluids are much higher. The movement of heat during convection coincides with conduction [1]. Currently, $90 \%$ of all radiators that are installed are plate radiators that are flat. They are characterized by low weight, low water content, nice appearance, large heat transfer surface, wide range of dimensions. The surfaces of the radiators can be smooth or wavy. There are solutions one and several rows. The front of these radiators gives off the heat by radiation and convection while the rear of the radiator mostlyby convection [2].

* Corresponding author: magdalena.orlowska@tu.koszalin.pl 


\section{Methodology of numerical research}

All simulations were performed using the simulation code Ansys Mechanical APDL/CFD Flo Preferences for GUI Filtering Flotran CFD 2D Flotran 141 Library of Elements Types [3].

„The program is based on solving the balance equations of energy, momentum and mass used in CFD- Computational Fluid Dynamic model. The standard version of the simulation code allows you to conduct modeling based on traditional dependence phenomenological equations and additional closures, describing the previously mentioned turbulent momentum and energy streams. The test system was modeled in two-dimensional space. Program calculates after entering the boundary conditions: temperature of the walls of the heat exchanger, room air velocity.The article presents couple of selected systems with different geometry attempted to explain its effects on the intensity of heat exchange (heat transfer coefficient)" [4,5].

\section{Results}

The numerical analysis include in this issue refers to the proposed three heights of the location of the heater $x$ at the wall $\left(x_{1}=1 \mathrm{~cm} ; x_{2}=2 \mathrm{~cm} ; x_{3}=2,5 \mathrm{~cm}\right)$ Fig. 1 with the differentiated temperatures surface set on the walls.

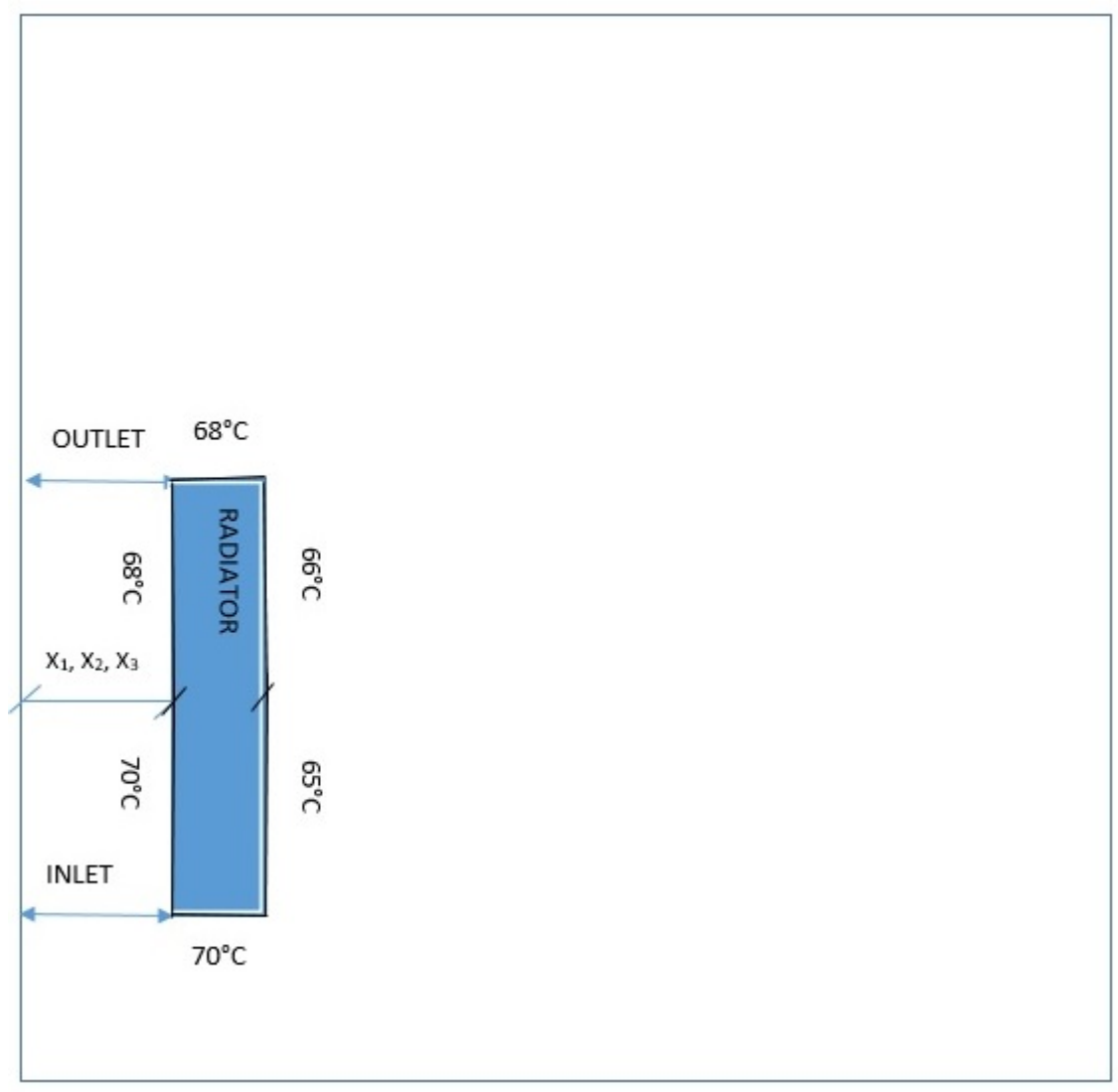

Fig. 1. The scheme of testing stand. 
Suggested distances let you determine which of the systems under test is the most efficient in terms of unit efficiency and thus the energy efficiency of the heat exchanger.

The numerical analysis gave the fallowing results Fig. 2,3,4,5,6,7.

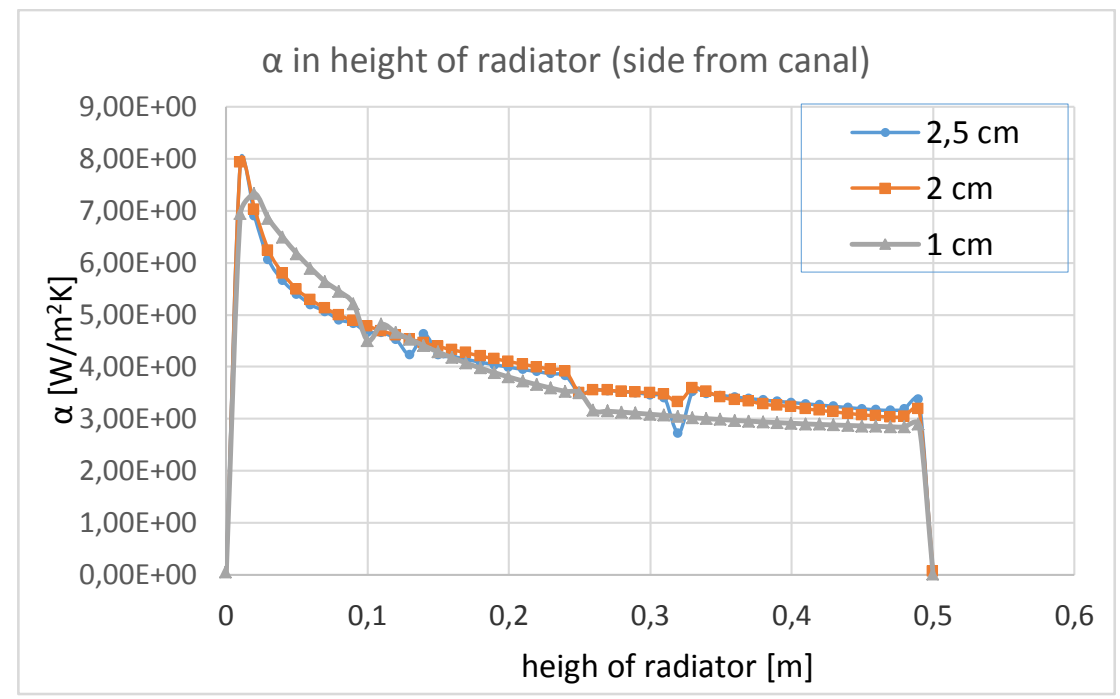

Fig. 2. Heat transfer coefficient $\alpha$ in height of radiator function.

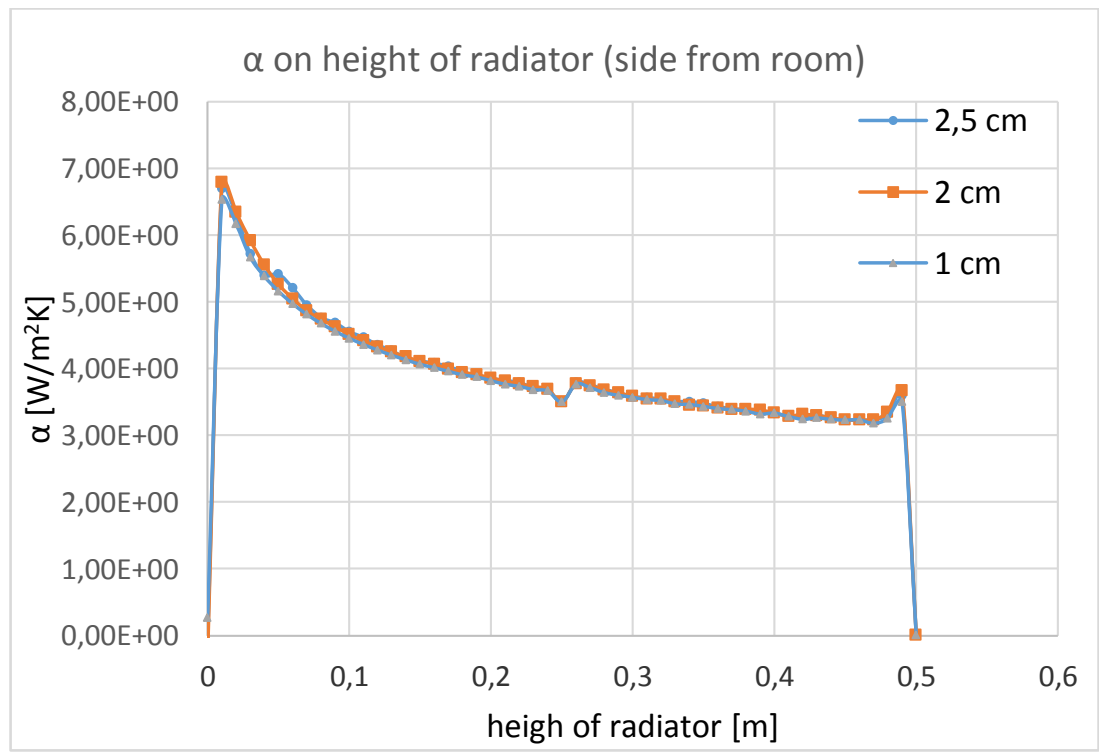

Fig. 3. Heat transfer coefficient $\alpha$ in height of radiator function (side from the room) 


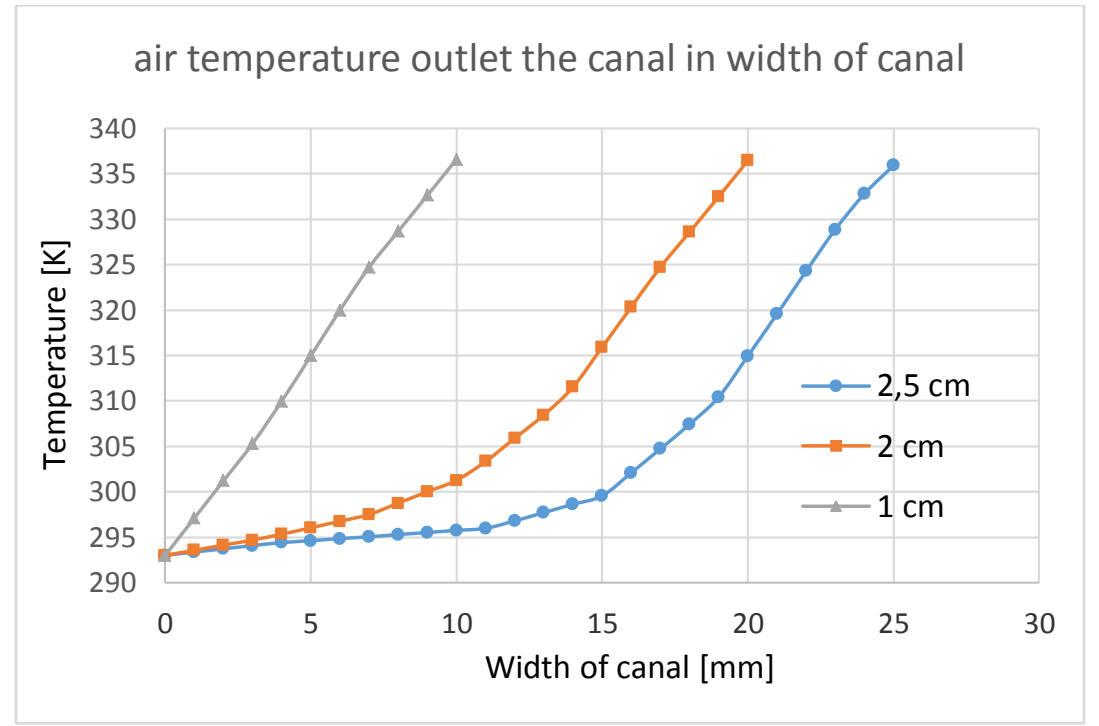

Fig. 4. Air temperature outlet the canal in width of canal function

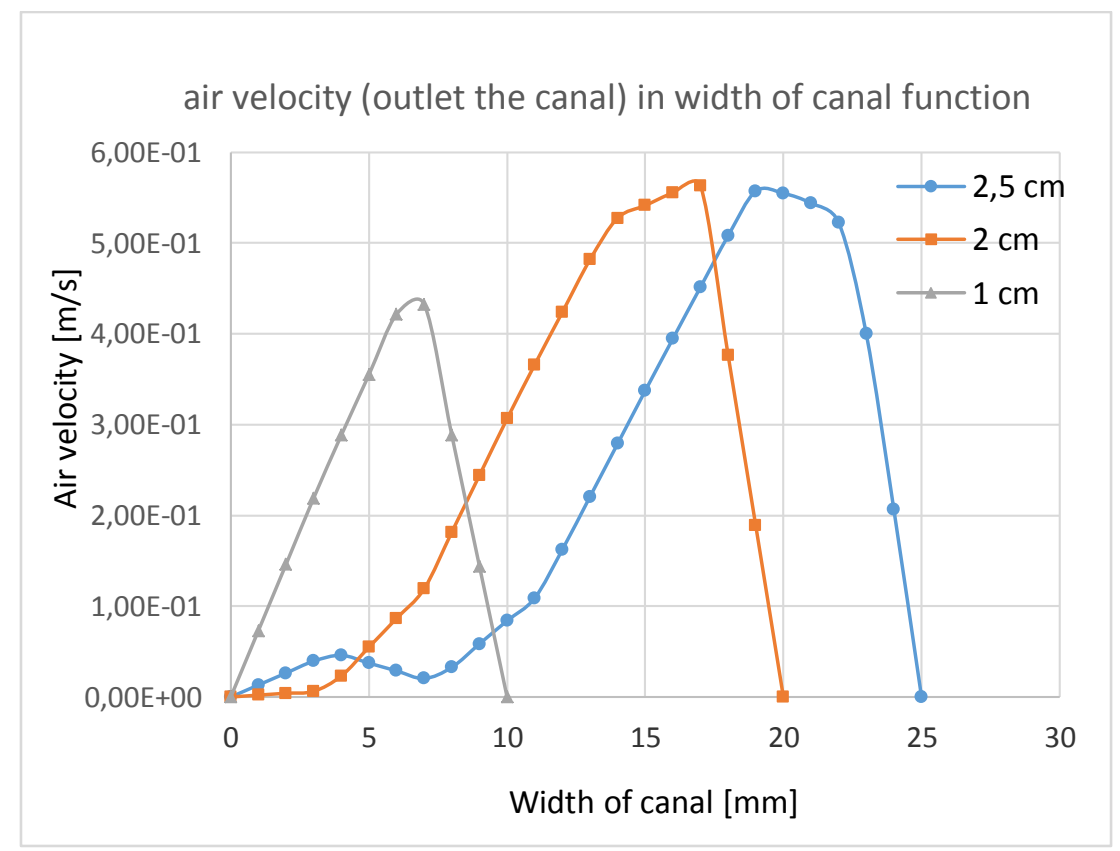

Fig. 5. Air velocity outlet the canal in width of canal function 


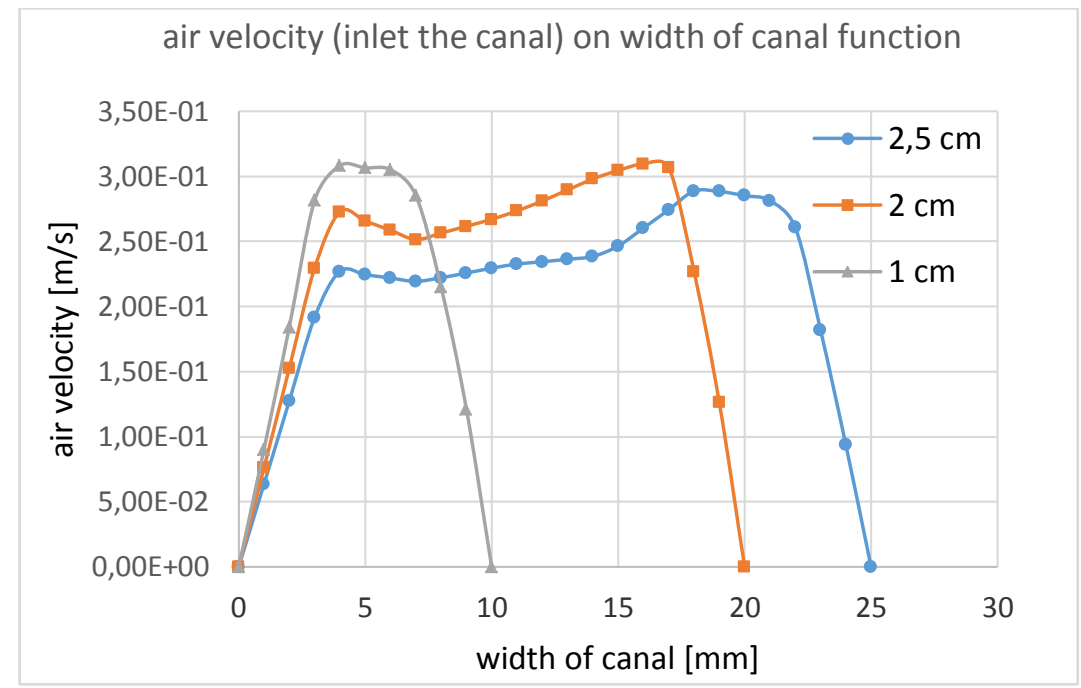

Fig. 6. Air velocity inlet the canal in width of canal function

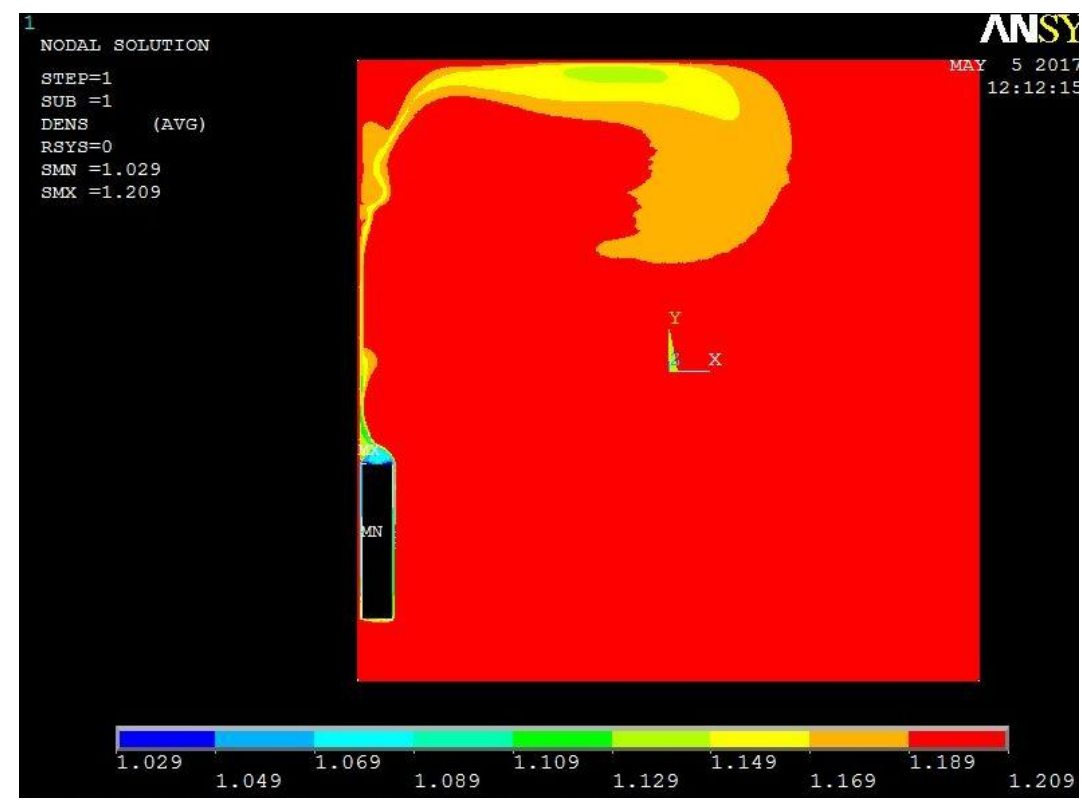

Fig. 7. Air density of testing model, [3]

\section{Discussion on the obtained results}

The best results in terms of heat output and therefore the heat transfer coefficient for the heater channel side were obtained in a system with $2 \mathrm{~cm}$ distance from the heater to the wall and it was $\alpha=3,93\left[\mathrm{~W} / \mathrm{m}^{2} \mathrm{~K}\right]$, slightly lower in a $2,5 \mathrm{~cm}$ distance $\alpha=3,89\left[\mathrm{~W} / \mathrm{m}^{2} \mathrm{~K}\right]$ and the lowest in a distance of $1 \mathrm{~cm} \alpha=3,77\left[\mathrm{~W} / \mathrm{m}^{2} \mathrm{~K}\right]$

In terms of the temperature at the outlet of the channel most preferred system was the arrangement of $1 \mathrm{~cm}$ distance, where the temperature was $314,92 \mathrm{~K}$, did slightly less variant 
with a distance of $2 \mathrm{~cm} 307,08 \mathrm{~K}$ and the lowest value was obtained at a distance of $2,5 \mathrm{~cm}$ $304,2 \mathrm{~K}$.

The velocity at the outlet of the duct was the highest because the outlet was $\mathrm{w}_{\text {wylot }}=2,41 \mathrm{~m} / \mathrm{s}$ reached in a system with a $2 \mathrm{~cm}$ distance between the wall and the heater, the lower at 2,5 $\mathrm{cm}$ of the slope $\mathrm{w}_{\mathrm{wylot}}=2,17 \mathrm{~m} / \mathrm{s}$ the lowest slope $\mathrm{w}_{\text {wylot }}=2,15 \mathrm{~m} / \mathrm{s}$ in a layout with a distance of $1 \mathrm{~cm}$.

The highest inlet velocity reached in the system with a $2 \mathrm{~cm}$ distance to the inlet $\mathrm{w}=2,24$ $\mathrm{m} / \mathrm{s}$, lower in the variant with $2,5 \mathrm{~cm}$ inlet distance $\mathrm{w}=2,06 \mathrm{~m} / \mathrm{s}$ and lowest in the system with

$1 \mathrm{~cm}$ distance to the inlet $\mathrm{w}=1,91 \mathrm{~m} / \mathrm{s}$.

The article shows the optimal distance (in terms of the heater's thermal performance) from the radiator's distance traveled. It is important that this performance is maximized.

It turns out that the influence of the environment is affected by it. It is not only about the distance of the radiator from the wall, but also the distance from the floor, from the window sill, the width and shape of the window sill. The radiator elements such as - decorating, and architectural assembly and mounting walls also affects performance. Most often it is a wall under the window and it is certainly better in terms of performance than a wall without a window. So, deciding on the location we should take into account not only the selection of suitable for the room of the heating power, which the radiator should provide but also rethink the mounting conditions, which remain insignificant.

\section{Conclusion}

Among the systems proposed in this study most preferred option is with a distance of $2 \mathrm{~cm}$ between the wall and the heater and this is the optimal distance. The layout with $1 \mathrm{~cm}$ distance could cause interference in the boundary layer hence the low values of the obtained parameters. In turn, the $2,5 \mathrm{~cm}$ system is already too far away, although it is only $0,5 \mathrm{~cm}$ away from the most advantageous variant.

Based on the numerical analysis, it can be said with absolute certainty that the radiator's distance from the wall to the temperature and air velocity fields and the efficiency of the device is affected. So consider the location of the heat exchanger before installing it.

\section{References}

1. A. Skoczylas, Przenoszenie ciepła, Oficyna Wydawnicza Politechniki Wrocławskiej, p.11, (1999)

2. M.B. Nantka, Ogrzewnictwo i ciepłownictwo, Volume II, Wydawnictwo Politechniki Śląskiej, p.27-28, (2010)

3. Ansys CFD, ver.12,1, Mechanical APDL Product Launcher, User Instruction

4. M. Orłowska, Numerical analysis of the heat exchanger energy efficiency depending on location from the floor, E3S Web Conf. Volume 17, $20179^{\text {th }}$ Conference on Interdisciplinary Problems in Environmental Protection and Engineering EKO-DOK 2017, (2017)

5. M. Orłowska, Numerical analysis at a plate heat exchanger with covers-selected variations, Heat Transfer and Heat Exchangers -Heat Transfer and Renewable Sources of Energy HTRSE 2016, p. 225-228, (2016) 